\title{
The Contribution of Formal Schooling to the Increase in Intellectual Capital
}

TORSTEN HUSÉN

Substantial IQ gains from one generation to the next have been recorded for men in many industrial societies since the 1950s. Some authors have attempted to argue away these results by claiming that intelligence tests do not measure general IQ but rather something with a weak causal link to IQ. Others have taken the evidence emerging from, for example, The Netherlands as showing that the massive increase in the nation's intellectual capital is accounted for by environmental factors, not the least of which is formal schooling. By using the Linear Structural Relations (LISREL) method and longitudinal data collected in Sweden for a male cohort, the influences of home background and formal schooling on adult IQ test scores are estimated. This study shows the importance of formal schooling in enhancing the intellectual capital of a nation. The implications for educational policy and practice are discussed.

Educational Researcher, Vol. 20, No. 7, pp. 17-25

$\mathbf{T}$ he influence of formal schooling on IQ test scores is a crucial problem in psychological research relevant to education. This issue has been given increased visibility by a recent study of the stability of IQ conducted by Flynn (1987). He compares generational changes in IQ test scores collected over time for representative samples in 14 industrial societies. The data show average IQ gains ranging from 5 to 25 points on a scale with a mean and a standard deviation of 100 and 15 , respectively. The median gain across countries is 15 points, or a full standard deviation (Flynn, 1987, p. 184). Rather than interpreting the results as indicating that IQ has increased from one generation to the next, the author questions the validity of certain group intelligence tests, such as the Ravens Progressive Matrices Test. In this connection, it may be mentioned that the feasibility study conducted by the International Association for the Evaluation of Educational Achievement back in the early 1960s showed that, contrary to expectations, the "culturefree" items such as Raven's Matrices were found to have more cross-national variance than did the verbal tests (Foshay, 1962).

On the basis of indirect evidence, Flynn then argues that a substantial portion of the IQ gains observed in the data are accounted for by unidentified, environmental variables. For example, the data collected in the Netherlands from 1952 to

\author{
ALBERT TUIJNMAN
}

1984-1982 are considered to "prove the existence of unknown environmental factors so potent that they account for 15 of the 20 points gained" (Flynn, 1987, p. 171). In passing, Flynn (1987, p. 188) mentions two variables, father's occupation and the child's level of formal education, which may have produced significant IQ gains in the Netherlands. Previous investigations have shown that such variables account for IQ gains and losses over time (Emanuelsson \& Svensson, 1985), even in those cases where repeated measurements on the same cohort are made longitudinally (Bergman, 1973; Finch, 1946; Härnqvist, Husén, 1950; Lund \& Thrane, 1983).

Flynn (1987) has to be commended for collating relevant information on secular trends in mean performance on (usually) group intelligence tests. The information, on the whole, is of a cross-sectional nature, that is, pertaining to successive age cohorts, such as young men tested in connection with registration for military service. By comparing age groups which have taken the same test, he establishes time series of comparable mean scores. The purpose has apparently been to subject conventional intelligence tests to a critical scrutiny. The author casts some doubt upon "what IQ tests really measure" and concludes that such tests "do not measure intelligence but rather a correlate with a weak causal link to intelligence" (Flynn, 1987, p. 190). He goes on to say: "Environmental factors with a large impact on IQ have not been identified" (p. 190). But the most important single factor identified in previous longitudinal studies is formal schooling. Unfortunately, Flynn does not elaborate on the expansion of formal schooling in most industrial societies as a possible explanation.

In the early 1950s, Husén (1953) noted that most of the well-controlled studies investigating the influence of school-

TORSTEN HUSÉN is Professor Emeritus at the Institute of International Education, University of Stockholm, 10691 Stockholm, Sweden. Specializations: comparative education, educational planning. AlBERT TUINMMAN is Assistant Professor in the Department of Education, University of Twente, PO Box 217, 7500 AE Enschede, The Netherlands. Specializations: adult education, research methodology in education. 
ing on IQ development in children had dealt with the influence of preschool and primary school teaching. At that time, only a few studies had been conducted where the first testing had taken place at the primary school age, and the second at adult age (cf. Skeels, 1942, 1965). Much later, Hyman, Wright, and Reed et al. (1975), Härnqvist (1977), Wolfle (1980), and Härnqvist (1989) observed that the enduring effects of schooling on verbal ability and other cognitive traits still constitute a neglected area of educational research. Although there is abundant evidence to support the claim that students make significant gains in verbal skills during their school career, rather little is known about the long-range general cognitive outcomes of formal schooling once individuals are separated from educational institutions (Wolfle, 1980).

\section{Purpose of the Study}

The present investigation sets out to estimate the influences of home background and formal schooling, respectively, on IQ test scores, by using longitudinal data collected in Sweden for a male cohort $(N=671)$ tested with a group test in 1938 at 10 years of age in the third grade of primary school, and retested with a similar set of four tests 10 years later at induction into military service.

The data were first collected and analyzed by Husén (1950, 1951a), who showed a substantial schooling effect on IQ assessed at 20 years of age. Härnqvist (1959), who reanalyzed the data set using a more stringent statistical method and controlling for the effect of primary school marks, found a slightly less substantial schooling effect. Because the present study employs the same data set, its focus is not only on substantive issues but also on methodological ones. By using the LISREL method (Jöreskog \& Sörbom, 1989), the study demonstrates the significance of advances in statistical analysis made since the early 1950 s.

\section{The Nature-Nurture Debate}

The development of the so-called Stanford-Binet Test (Binet \& Simon, 1905; Terman, 1916) gave momentum to the measurement of individual differences in cognitive characteristics. This movement was shortly followed by the development of group tests of intelligence, such as the famous Army Alpha Test used during World War I. At that time, intelligence test scores were often believed to express largely the hereditary potential. Hence, intelligence test scores were expected to remain fairly constant throughout life. However, during the 1920s and 1930s, some researchers began to argue that substantial upward or downward shifts in measured IQ could be expected as a result of major environmental changes in the lives of children. The results of studies reviewed in Jones (1946) indicated not only that IQ was not constant, as was generally believed at the time, but also that IQ development in children and adults was closely related to factors in the social environment (Bloom, 1964; Husén, 1974).

The question thus arose as to which environmental factors influenced IQ development in children. It was argued that the school produced significant changes in IQ. Other took the correlation between school achievement and IQ test results as an indication that group tests were invalid because they did not measure "innate ability" but, rather, the cognitive outcomes of schooling. In this connection it can be mentioned that Cronbach (1960) and Bloom (1964) found that intelligence tests given in adolescence and early adulthood are highly saturated with verbal ability. Thus, there clearly is a need to control for differences in formal schooling when examining the stability of IQ.

\section{Previous Studies: Their Findings and Implications}

The estimation of the influence of schooling on IQ test scores is beset with numerous conceptual and methodological problems. These concern not merely the definition and measurement of intelligence. Other problems arise because factors such as home background and work situation influence the relationship between schooling and adult IQ. In this regard, previous studies have frequently noted the possibility that omitted factors may bias results obtained in the estimation of parameters in path models, because large but spurious effects of schooling may be found as a consequence of specification error and selection bias. Moreover, the effect of schooling on adult IQ cannot be interpreted without reference to some standard. Hence, appropriate controls for the influence of child IQ are needed. Accordingly, the study of the influence of formal schooling on adult IQ involves the investigation of at least four relationships: (a) the effects of home background on a child's tested IQ and formal schooling; (b) the effect of a child's tested IQ on school learning; (c) the effect of a child's tested IQ on adult IQ test scores; and (d) the effect of formal schooling on adult IQ test scores.

In the 1970s, several meta-analyses were conducted of studies carried out predominantly in the United States of factors influencing student learning. On the basis of reviews of these studies, Haertel, Walberg, and Weinstein (1983) and Fraser, Walberg, Welch, and Hattie (1987) identified nine factors operating to increase learning. These were categorized under three broad headings: environment, aptitude, and instruction.

Environment, as used in educational research, is a multifaceted concept comprising a complex cluster of factors. These include characteristics of the home, the classroom, the peer group, the surrounding community, and the mass media. However, only the first are commonly specified in path models. Some authors refer to home background factors as the social, cultural and economic, or human "capital" of the home (Bourdieu, 1977; Coleman, 1988; Lesourne, 1979). Fraser et al. (1987) distinguish among three dimensions of student aptitude. These are cognitive ability, maturation, and motivation. It is generally difficult to identify the appropriate point in the lives of students at which these variables should be measured in a path model that follows a conceptual sequence ordered in time. Because of this complication, indicators of student motivation and maturity are not commonly specified in educational attainment models. However, IQ test scores are frequently included.

Studies of the relationship between IQ test scores obtained in childhood and formal educational attainment measured in terms of years of schooling have generally recorded substantial positive correlations (Behrman, Hrubec, Taubman, \& Wales, 1980; Boissiere, Knight, \& Sabot, 1985; Bound, Griliches, \& Bronwyn, 1986; Fägerlind, 1975; Hauser \& Sewell, 1986; Jencks et. al., 1979). Dependent on properties of measurement and on characteristics of the countries in which the data are collected, these correlations lie between 0.45 and 0.55 . Some authors argue that the effect of tested IQ on educational attainment derives in part from environmental factors. The use of home background or socio- 
economic status (SES) as a predictor of both cognitive ability and educational attainment reduces the predictive capacity of IQ test scores. As the correlation between father's education and SES, on the one hand, and a child's IQ test scores, on the other, typically reaches values around 0.30 , it may be concluded that environmental influences are implicated in the relationship between tested IQ and schooling outcomes (Härnqvist, 1989; Jencks et al., 1979; White, 1982; Williams, 1976; Zajonc \& Bargh, 1980).

Anastasi (1958a, 1958b), Bloom (1964), McCall, Appelbaum, and Hogarty. (1973), Husén (1974) Jencks et al. (1979), and Anastasi (1988) reviewed an extensive body of data showing that IQ test performance is quite stable over the period of formal schooling up to the point where youth enter college. ${ }^{1}$ Terman and Oden (1947) reported a study in which a group of high-IQ children identified very early in life was followed up for over 30 years. The children included in the group initially had an IQ over 140 . Hence, as the group was positively selected to a high degree with a strong restriction of range, the influence that differences in formal schooling may have had in this group can by no means be generalized to a normal population. Nevertheless, this study is important because it demonstrates the existence of a substantial regression effect. Bayley (1949) conducted a longitudinal study of a well-defined group of children from birth to 18 years of age. She found that IQ measured at four years of age has a strong correlation with IQ tested at 17 years of age (0.71). By the age of 11 years, the product-moment correlation with the test given at 17 years of age had increased to 0.92. Bradway, Thompson, and Cravens (1958), who followed up on a group of children originally tested between the ages of 2 and 5 years of age until 14 and 29 years of age, found a simple correlation between the 10-year retest and the 25 -year retest of 0.85 . Bloom $(1964$, p. 61) concluded his survey of studies on the stability of IQ as follows.

...the correlation between intelligence (when ideally measured) at age 3 and age 17 is about 0.65 , between intelligence measured at age 5 and age 17 is about 0.80 , and between intelligence measured at age 8 and age 17 is almost 0.90 . After age 8 , the correlations between repeated tests of general intelligence should be between 0.90 and unity.

The effect of schooling on IQ was studied by Lorge (1945), who used test scores obtained in 1921-1922 and in 1944 for 131 men who, at the occasion of the first testing, attended the eighth grade of a primary school in New York City. The approach taken by Lorge was to determine group mean scores for the various levels of schooling received. He found that higher levels of schooling were associated with significant increases in IQ test scores. Husén (1950, 1951a) studied the influence of schooling upon IQ by using data collected for the Malmö Study. He concluded (Husén, 1951a):

...there is reason to suppose that theoretical schooling, subsequent to leaving the primary school, considerably increases the intellectual level, which is measured with group tests of a conventional type. On an average, the increase lies between zero and 10 IQ units, according to the scope of schooling. On average, the increase amounts for all who have received some form of further schooling to 4.84 units. The senior secondary schooling, raises the level, on an average, by $7-10$ units. (pp. 75-76)

Härnqvist (1959) employed data gathered for a representative Swedish sample of 7,110 boys for comparisons between groups with different levels of formal education; he related test scores at the age of 19-20 years to school marks obtained eight years earlier. The analysis of covariance showed marked differences in IQ gains between higher and lower education groups. For example, higher education was found to raise IQ in the population by an average 12.2 units (Härnqvist, 1959, p. 67). A decade later, Härnqvist (1968) reported a correlation of 0.78 between two IQ tests given to 4,616 Swedish men at 13 and 18 years of age, respectively. By using the analysis of covariance (ANCOVA) method (Finn, 1988), a score of 55 was found for the difference in the school effect between a higher and a lower educational group, expressed as a percentage of the standard deviation of the total distribution of observed test scores for the study sample.

Lund and Thrane (1983) used data initially collected in 1953 for a Norwegian representative sample of 7,703 boys and girls. The children were tested with six military classification tests in grade seven, at the end of primary school. The mean age was 13.8 years at the occasion of the first testing. The same tests were given to 3,400 of the boys five years later at the average of 18.9 years in connection with their induction into the Norwegian Armed Forces. The study presents an analysis of data examining the effect of schooling on adult test scores for a representative subsample of this group, comprising 2,485 boys for whom full information regarding educational careers was available. They found that the difference in the estimated effect between a higher and a lower educational group varied from $49 \%$ to $73 \%$ of the pretest standard deviation, which is higher than the result found by Härnqvist (1968) but lower than that found by Husén (1951a). Moreover, substantial changes from pre- to posttest were observed, the mean gain amounting to $114 \%$ of the pretest standard deviation (Lund \& Thrane, 1983).

\section{Hypothesized Model}

The model investigated in this article comprises four constructs: (a) home background, (b) tested cognitive ability at 10 years of age, (c) formal educational attainment, and (d) tested cognitive ability at 20 years of age. A causal structure can be hypothesized between these variables, as is shown in Figure 1. The model is developed for the dual purposes of studying the stability of IQ between ages 10 and 20 , as well as the predictive capacity of home background and formal educational attainment in influencing IQ. The model is recursive, with both a temporal and a conceptual sequence determining the ordering of the variables. A pathway of influence is hypothesized as follows:

Hypothesis 1. Home background has significant direct effects on intelligence test scores at the age of 10 years and formal educational attainment, but not on cognitive ability tested at 20 years of age because this effect is mediated by other factors.

Hypothesis 2. Cognitive ability at age 10 has a significant direct effect on formal educational attainment and both a direct and an indirect effect on cognitive ability at age 20 .

Hypothesis 3 . Formal educational attainment has a significant direct effect on cognitive ability at age 20 . 


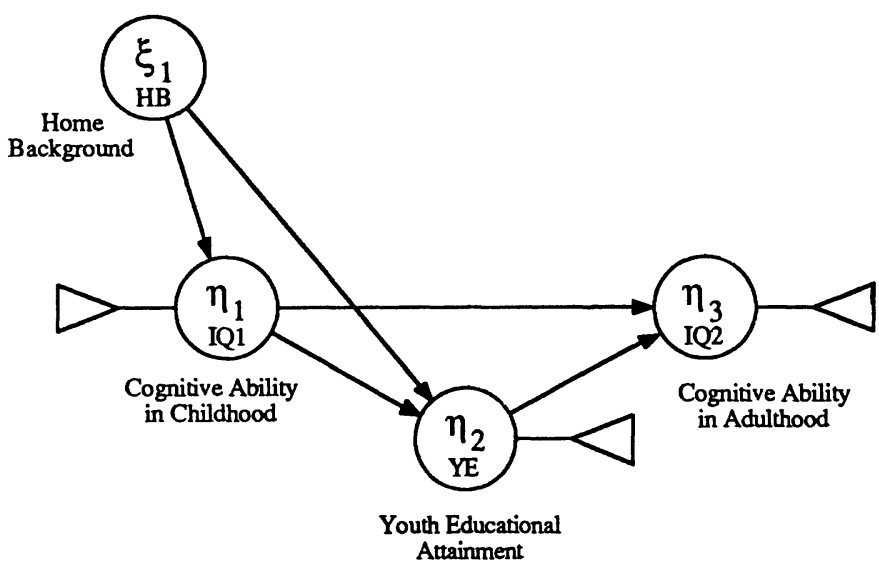

FIGURE 1. A hypothesized model of the influence of schooling upon measured intelligence.

\section{Sample and Data Collection}

The Malmö Study was initiated by Hallgren in 1937. His intention was to investigate the relationship between home background and cognitive ability (Hallgren, 1939; Husén, 1950; Husén, Emanuelsson, Fägerlind, \& Liljefors, 1969). In 1938, a group intelligence test was administered to all the 1,542 students attending the third grade in all public and private schools in the city of Malmö in southern Sweden. The group consisted initially of 834 boys and 708 girls. Hallgren also collected data about the students' home background, because he intended to study the relationship between social background and IQ test scores. In 1942, the first follow-up traced the school careers of boys who transferred to the junior academic secondary school (Hallgren, 1943).

In 1948, another opportunity for data collection arose because all 20-year-old men, including those surveyed in the Malmö Study, were required to appear before military conscription boards. On that occasion, most boys were given a group intelligence test comprising four test categories (Husén \& Henricson, 1951). Husén (1950) used test scores for 613 of the 717 normal-aged youth in the Malmö Study and for 40 over-aged youths. Besides IQ test scores, Husen also extracted information from military records about educational and occupational careers up to the age of 20. In spite of the loss of some cases, those for whom test scores were collected were shown to be representative of the original population (Husén, 1950). ${ }^{3}$

Data concerning educational careers were gathered mostly from public records up to the late 1950s. In 1963, the data were supplemented with information about formal schooling collected by means of a questionnaire. Since then, the cohort has been followed up on several different occasions. Tuijnman (1989) conducted analyses of data collected as late as in 1984 and 1988. It is important to note that the men followed up in the Malmö Study had received eight years of schooling on average. The few men who had pursued university studies were, in 1948, already found in the highest category of educational attainment. Hence, the small overlap in time between the schooling variables and the IQ test given at 20 years of age does not disturb the validity of the analysis of data conducted for this article.

A data set with full coverage on all measures was built up for 671 men in the way described above. This group was shown empirically to be representative, at least to a satisfactory degree, of the cohort originally defined in the Malmö Study in 1938 (Tuijnman, 1989).

\section{Method}

It is outside the scope of this article to discuss the Linear Structural Relations (LISREL) approach to multivariate data analysis. Its assumptions, methods, and notation system are described in Jöreskog and Sörbom (1989). It will be sufficient to mention here that the LISREL 7 computer program was employed in the fitting of data to the model, using productmoment correlations and the maximum likelihood fit function. This method has several advantages. First, because the reliability of the tests used in 1938 is unknown, the LISREL method can be used to estimate them. A second advantage is that it can provide one path coefficient summarizing the influence of schooling upon IQ test results. Third, the technique provides an estimate of the overall goodness of fit of the model, so that there is an indication as to whether the model can be considered appropriately specified. Among the disadvantages can be mentioned that the factor loadings and path coefficients obtained in LISREL models are distant from realities on which they are based (Freedman, 1987) and thus present some interpretative difficulties (Härnqvist, 1989).

In short, LISREL notation is explained as follows: $\eta$ denotes the latent variable, $\zeta$ refers to the residual variance in a latent variable, and $\varepsilon$ indicates the measurement error in a manifest or observed variable.

\section{Manifest Variables}

Twelve measures were used to estimate the four latent variables included in the theoretical model (see Figure 1).

Father's educational attainment is measured on a six-category scale (Fägerlind, 1975), and father's occupational status on a five-point scale. The categories are assigned rank scale scores as follows: $5=$ upper and upper middle class; $4=$ nonmanual employees, clerical workers in services, sales and administration, and higher grade technicians; $3=$ skilled manual workers; $2=$ semi-skilled manual workers; and $1=$ unskilled manual workers. Father's income includes income from wages, self-employment, and income from capital and transfer payments in 1937.4

Cognitive ability in childhood (at 10 years of age) is measured by a group intelligence test constructed for the Malmö Study. The four test components are (a) word opposites, (b) sentence completion, (c) perception of identical figures, and (d) restoring disarranged sentences (Hallgren, 1939).

Acquired level of formal education consists of six levels of formal educational attainment: $6=$ some university education; $5=$ matriculation examination from academic secondary school; $4=$ incomplete upper secondary education; $3=$ lower secondary education, including some vocational training; 2 =seven years of compulsory schooling; and $1=$ left school at 14 years of age, when attendance was no longer compulsory.

Cognitive ability in adulthood (at 20 years of age) measured by a group intelligence test developed for use by the Swedish military. The 1948 test has four subtests: (a) synonyms, (b) concept discrimination, (c) number series, and (d) matrices (Husén \& Henricson, 1951, p. 26).

\section{Results}

Table A1 in the Appendix presents product-moment correla- 
tions involving 12 manifest variables. The matrix is used as the input into the LISREL 7 computer program. A multistage approach was taken in the fitting of the model to the data. ${ }^{5}$ In an earlier study (Fägerlind, 1975) employing data derived from the Malmö Study, a correlation of 0.75 was found between aggregate and normalized indicators of child IQ and adult IQ. ${ }^{6}$

The path diagram in Figure 2 shows the central findings emerging from the analysis of data. Significant parameters and their standardized path coefficients are indicated. ${ }^{7}$ It can be seen from the diagram that the residual in child IQ is $88 \%$. Hence, home background (HB) explains $12 \%$ of the variance in child IQ tested at 10 years of age. The path coefficient found for the influence of home background on child IQ is 0.35 , which is consistent with previous research. About half $(0.50)$ of the variance in youth educational attainment (YE) is accounted for by two predictor variables. While the influence of home background on youth educational attainment is 0.45 , that of the effect of child IQ is 0.41 .

The absence of a path from home background to adult IQ indicates that this influence is not significant once variations in child IQ and formal schooling are held constant. ${ }^{8}$ However, the estimates recorded in Appendix B, which indicate the magnitude of the direct, indirect, and total effects of the antecedent variables on adult IQ, reveal that the total effect of home background on adult IQ is substantial (0.43). ${ }^{9}$ It can be seen from the residual (0.13) in adult IQ in Figure
2 that early cognitive ability and youth educational attainment explain $87 \%$ of the variance in this dependent variable. The effect of child IQ on adult IQ is highly significant $(0.71)$, while that of schooling is moderate $(0.33)$. The path coefficient $(0.71)$ estimated in the present investigation is the same as that $(0.70)$ found by Wolfle (1980)..$^{10}$

Besides the coefficients of determination associated with the dependent variables, Table 1 also presents the "true," or corrected, correlations among the theoretical variables included in the structural model. ${ }^{11}$ It is of interest to note that the correlation ( 0.57 ) between child IQ and schooling is not as strong as that $(0.73)$ between schooling and adult IQ. This finding is further qualified because the correlation between home background and adult IQ (0.44) is also greater than the one between home background and child IQ $(0.35)$. The estimated correlation between the variables indicating child IQ and adult IQ is 0.89 . This estimate is of interest because Bloom (1964) and Jencks et al. (1979, p. 97) point out that correlations between early adolescent IQ and adult IQ are typically at least $0.80 .{ }^{12}$

The results generally support the hypotheses advanced earlier in this article. Home background is found to have significant direct effects on both child IQ and early formal schooling. The direct effect of home background on adult IQ is, as was expected, not statistically significant. Thus, Hypothesis 1 is confirmed by the analysis of data. Hypothesis 2 is also supported by the evidence, because child IQ exerts



Figure 2. Parameter estimates in a model examining the effect of schooling on adult IQ test scores.

Note. Table 1 presents summary statistics for the measures included in the model. All parameters shown are statistically significant, at least at the .05 level. Maximum likelihood, standardized solution. The goodness of fit of the model to the data is adequate $\left(\chi^{2}\right.$ is 37.8 with 40 degrees of freedom and probability .57). Asterisk $\left({ }^{*}\right)=$ fixed parameter; $\eta_{1}=$ home background (HB); $\eta_{2}=$ cognitive ability at age 10 (IQ1); $\eta_{3}=$ youth educational attainment $(\mathrm{YE}) ; \eta_{4}=$ cognitive ability at age $20(\mathrm{IQ} 2) ; Y_{1}=$ father's occupational status; $Y_{2}=$ father's educational attainment; $Y_{3}=$ father's income; $Y_{4}=$ subtest involving sentence completion; $Y_{5}=$ subtest involving sentence restructuring; $Y_{6}=$ subtest involving word opposites; $Y_{7}=$ subtest involving figure perception; $Y_{8}=$ level of formal youth education acquired; $Y_{9}=$ subtest involving concept discrimination; $Y_{10}=$ subtest involving number series; $Y_{11}=$ subtest involving word synonyms; $Y_{12}=$ subtest involving matrices. 


\section{Table 1}

\section{Estimated "True" Correlations and Coefficients of Determination $\left(R^{2}\right)$ Among Theoretical Variables}

\begin{tabular}{lccccc}
\hline \multicolumn{1}{c}{ Theoretical variable } & 1 & 2 & 3 & 4 & $R^{2}$ \\
\hline 1. Home background (HB) & 1.00 & & & & na \\
2. Cognitive Ability (IQ1) & 0.35 & 1.00 & & & 0.12 \\
3. Youth education (YE) & 0.60 & 0.57 & 1.00 & & 0.50 \\
4. Cognitive ability (IQ2) & 0.44 & 0.89 & 0.33 & 1.00 & 0.87 \\
\hline
\end{tabular}

Note. The correlations are estimated by using the maximum likelihood method. Measurement errors and significant error covariance terms are taken into account. The coefficient of determination $\left(R^{2}\right)$ denotes the amount of variance (per cent) explained by explanatory variables in the dependent variable. NA $=$ not applicable.

substantial effects on schooling and adult IQ. Finally, the results demonstrate that schooling has a direct effect on adult IQ, even after variations in home background and child IQ are held constant. Hence, Hypothesis 3 is confirmed.

Consequently, the study supports the conclusion drawn by Husén (1951a) and Härnqvist (1968) that not only child IQ has an effect on schooling outcomes but also that schooling per se has a substantial effect on IQ tests scores. Hence, schools not only confer knowledge and instrumental qualifications but also train and develop students' intellectual capacity. The results provide support for the thesis advanced by Husen (1951a) that IQ as measured by group intelligence tests is not stable but changes significantly between 10 and 20 years of age. Husén's (1951a) argument that the amount and quality of schooling experiences to which children are exposed are implicated in the observed changes in measured IQ is also confirmed. ${ }^{13}$

It can be concluded, at least on the basis of results obtained in the present study, that schooling covaries with and produces positive changes in adult IQ. This conclusion is justified because an unstandardized path coefficient with a value of 0.28 is obtained for the schooling-IQ effect (see Appendix $B$ ). It is of interest from a substantive view point and also in a cross-validation perspective to contrast this coefficient with the results of Härnqvist (1989), who, in a carefully designed longitudinal study, investigates the impact of schooling on self-rated adult capabilities reported by a cohort of 2,339 Swedish women and men born in 1948. The LISREL estimate of the direct effect of education on the general component of verbal and linguistic skills in adulthood is 0.20 for men and 0.24 for women. The difference between our result of 0.28 and Härnqvist's finding of 0.20 for the schooling effect must be considered small. ${ }^{14}$

\section{Implications}

The results reported in the present article have two implications of a fundamental import for educational policy and practice. First, the pool of ability from which the school system draws its students should not be conceived of as being predetermined and definite with regard to the number of those who can benefit from continuing academically oriented education. Secondly, the individual student is not predestined, when he or she enters school, to a particular educational and-in the long run-occupational career. Apart from imparting special competencies, the school, by its own actions, can enhance the individual's general intellectual ability and thereby his or her prospects for getting ahead in life. It seems worthwhile to discuss these general implications in the context of the nature-nurture controversy.

In the mid-1940s the senior author, who than as a graduate student had been involved in the initial (1938) collection of data for the Malmö study, had analyzed the survey data in order to assess the size of what was referred to as "the reserve of ability" (Husén, 1946; the summing up of several investigations in Husén, 1962). Advantage was taken of the availability of test data and information on education for almost complete age cohorts of 20-year-old young men examined for the Swedish Armed Forces. By relating IQ test scores to formal schooling, an attempt was made to estimate the percentage of an age group capable of meeting the intellectual requirements of upper secondary and/or higher education. The difference between this proportion and the proportion who actually passed the lower and/or upper secondary school examination defined the size of the "reserve."

At that time (late 1940s and early 1950s) a major structural reform of the Swedish school system, which would considerably increase secondary school enrollment and make it universal at the lower level, was in the planning and pilot stage. The objection was put forward against the reform, mainly in conservative quarters, that the reserve of ability would not suffice to increase access to academic schooling to the extent the reformers envisaged. A heated debate on this issue was going on when the first major follow-up of the primary school population tested initially in 1938 was published (Husén, 1950). The report happened to be released in the same year that the Education Act was passed in the Parliament, making provisions on a pilot basis for the introduction of comprehensive secondary schooling. The senior author published an article (Husén, 1951b) in the journal of the Swedish Primary School Teacher Association about the issue of the "reserve of ability." He wrote:

The ability resources that society possess are not constant over an indeterminate future. They constitute a "capital" that grows along with the increase of material and cultural standards. It would not be too far from the truth if we assume that by the beginning of this century only some 10-15 percent of all children would have been able to pass the secondary school examination. Presently we can on the basis of our own empirical research estimate that some 30 percent are capable to pass the examination. Within a few decades some 50 to 60 percent may be able to do so. It is, indeed, of 
the greatest importance to try to investigate how many children in our present society are able to benefit from furthergoing formal education. But today's estimations should not fatalistically be accepted as facts valid for the future society. When the comprehensive school once has been introduced all over the nation the auspices in terms of the number of capable students may be quite different. (p. 6)

Today, even upper secondary schooling has become almost universal in Sweden. Instead of catering to a small elite of some $10 \%$, it is now available to all young people up to the age of 18 or 19 . Instead of less than $10 \%$ qualifying for university entrance, now some $30 \%$ complete academic upper secondary courses and thereby gain eligibility.

About 1970, when the second major follow-up of the Malmö population was published (Husén et al., 1969), a heated debate had been elicited by an article in the Harvard Educational Review by Arthur Jensen (1969). At that time several Federal Compensatory Education Programs had been going on in the United States for some years. The philosophy behind them was that interventions by the school in terms of, say, tutorials and other individualized methods of instruction would compensate children from culturally and materially poor backgrounds for their handicap. Head Start was one of these programs. Jensen began his 123-page article, which was based upon a broad spectrum of previous studies (among them the ones conducted by Cyril Burt) in order to assess the "heritability" of IQ, with the provocative opening statement: "Compensatory education has been tried and it apparently has failed."

Since then, Flynn (1987), by using cross-sectional data sets from 14 countries, has shown that over a generation there has been an increase in IQ amounting to almost one standard deviation. ${ }^{15}$ This massive growth cannot possibly be explained by genetic factors and therefore has to be accounted for by changes in the environment, including schooling. However, Flynn does not discuss the influence of the latter, in spite of the enrollment explosion which has taken place over the last few decades when secondary school enrollment multiplied in many industrial societies and economic growth has led to a considerably increased standard of living. Nevertheless, he provides evidence of a pervasive trend of enhanced IQ and observes: "Just as an elite with a massive IQ advantage should radically outperform the rest of its generation, so a generation with a massive IQ gain should radically outperform its predecessors" (p. 187).

Thus, the prediction some 40 years ago that the proportion of students capable of furthering their education would double when the school reform had become fully implemented seems to hold up. The increase in intellectual capacity has considerably increased the number of young people who can benefit from further formal education, which in its turn enhances their career prospects in working life. The longitudinal data analyzed in the present article by using path analysis and the LISREL method show that there is a considerable margin for a nation's intellectual capital to be increased by means of formal schooling. This is so because the general intellectual level is enhanced irrespective of specific knowledge capital acquired by means of the various school subjects.

\section{Compensatory education has been tried, and it apparently has failed.}

The two implications spelled out are, of course, of great importance for educational policy in technology- and information-intensive societies. Even though a considerable number of low-competence service jobs will remain, the overarching problem in the labor market today is to recruit enough qualified persons for high-competence jobs. To use a crude metaphor: In modern society the "qualification pyramid" has been turned upside down. The elite is rapidly growing, whereas the mass at the bottom of the pyramid is becoming a minority, a "new underclass." Finally, it should also be pointed out that the intellectual capital of a nation is created not only through formal schooling during the first two decades of life. Since the 1950s adult education has increasingly become a dominant feature of the working life and the career of the individual.

\section{Appendix A}

Matrix of Product-Moment Correlation Coefficients $(N=671)$

\begin{tabular}{|c|c|c|c|c|c|c|c|c|c|c|c|c|}
\hline Variable & 1 & 2 & 3 & 4 & 5 & 6 & 7 & 8 & 9 & 10 & 11 & 12 \\
\hline 1. Father's occupation & 1.00 & & & & & & & & & & & \\
\hline 2. Father's education & 0.66 & 1.00 & & & & & & & & & & \\
\hline 3. Father's income & 0.71 & 0.48 & 1.00 & & & & & & & & & \\
\hline 4. Test A1: completion & 0.21 & 0.16 & 0.15 & 1.00 & & & & & & & & \\
\hline 5. Test A2: restructure & 0.20 & 0.15 & 0.14 & 0.62 & 1.00 & & & & & & & \\
\hline 6. Test A3: opposites & 0.25 & 0.17 & 0.19 & 0.58 & 0.51 & 1.00 & & & & & & \\
\hline 7. Test A4: perception & 0.22 & 0.10 & 0.19 & 0.45 & 0.46 & 0.37 & 1.00 & & & & & \\
\hline 8. Youth education & 0.52 & 0.45 & 0.39 & 0.43 & 0.43 & 0.41 & 0.36 & 1.00 & & & & \\
\hline 9. Test B1: concept & 0.35 & 0.30 & 0.25 & 0.63 & 0.56 & 0.57 & 0.42 & 0.63 & 1.00 & & & \\
\hline 10. Test B2: numbers & 0.35 & 0.29 & 0.29 & 0.55 & 0.58 & 0.52 & 0.46 & 0.59 & 0.75 & 1.00 & & \\
\hline 11. Test B3: synonyms & 0.34 & 0.25 & 0.26 & 0.55 & 0.51 & 0.52 & 0.47 & 0.59 & 0.68 & 0.66 & 1.00 & \\
\hline 12. Test B4: matrices & 0.27 & 0.20 & 0.22 & 0.45 & 0.46 & 0.46 & 0.43 & 0.53 & 0.55 & 0.60 & 0.68 & 1.00 \\
\hline
\end{tabular}




\section{Appendix B}

\section{Total (TE), Direct (DE), and Indirect (IE) Effects of Home Background, Child IQ, and Youth Education on Adult IQ (Standard Errors, SE)}

\begin{tabular}{lcccccc}
\hline & \multicolumn{7}{c}{ Dependent variable: Adult IQ, age 20 } \\
\cline { 2 - 7 } Antecedent variable & TE & SE & DE & SE & IE & SE \\
\hline Home background & 0.43 & 0.04 & $n s$ & & 0.43 & 0.04 \\
Child IQ (age 10) & 0.95 & 0.05 & 0.80 & 0.04 & 0.15 & 0.02 \\
Youth education & 0.28 & 0.03 & 0.28 & 0.03 & $n s$ & \\
\hline
\end{tabular}

Note. Trivial direct effects are denoted $n s$ (nonsignificant). Direct effect coefficients are unstandardized maximum likelihood estimates.

\section{Notes}

1Some studies examining the development of adult IQ over time seem to suggest that observed cognitive ability decrements formerly attributed to the aging process are most likely a result of cohort effects, associated with generational changes in school attainments (Nesselroade \& Von Eye, 1985; Schaie, 1983; Schaie \& Hertzog, 1986).

${ }^{2}$ Using different data sources and an artifically created matrix of product-moment correlation coefficients, Wolfle (1980) estimates the effects of schooling on adult IQ, controlling for the influences of variables such as child's IQ, age, sex, father's education, and father's socioeconomic status. A standardized path coefficient of 0.70 is found for the influence of child's IQ on adult IQ test scores. Furthermore, while a path coefficient of 0.19 is obtained for the effect of schooling on adult IQ, the effect of schooling on verbal skills is clearly not significant $(0.03)$.

${ }^{3}$ The possibility of contamination in responses elicited over time as a result of missing data is nowadays generally acknowledged (Kish, 1987). As is mentioned above, Husén (1950) obtained test scores for 643 of the originally 834 men. However, it should be noted that IQ test data were obtained only for those of normal age. The case loss poses both conceptual and analytical problems. In order to minimize these problems, a multistage procedure of compensation for missing data is employed in the present investigation (Kalton, 1983; Little \& Rubin, 1987; Tuijnman, 1989). The cohort was restricted from 834 to 671 men in the first stage of data compensation. The purpose was to achieve a sample frame that could be held constant over time. A second aim was to draw cases in such a manner that the group included could be considered to conform as closely as possible to a simple random sample taken from the 834 men initially surveyed in 1938. The aim of the second stage was to single out the records of specific respondents and to fill in the eventual gaps in the schooling variables by using auxiliary data available about the respondents.

${ }^{4}$ Jencks et al. (1979, pp. 8-9) mention several advantages of using the logarithm $(l n)$ of income instead of actual earnings. In this investigation $\ln$ income is also employed.

${ }^{5} \mathrm{~A}$ just-identified and fully recursive model was estimated in the first stage. Then, using $\chi^{2}$ tests, the measurement model was improved by freeing significant error correlations. Finally, those structural relationships which failed to pass the test used for determining statistical significance were deleted from the model. Accordingly, the path coefficient linking home background to adult IQ was fitted in an earlier version and omitted in the final estimation stage because of lack of significance. Moreover, each error correlation specified in the model was selected on the basis of a modification test involving a $\chi^{2}$ distribution with one degree of freedom, so that the significance of the error term was carefully checked against both a predicted and an obtained reduction in the $\chi^{2}$ distribution associated with the overall model. One implication of the procedure followed is that once the latent structure is accounted for, none of the residuals remaining in the measurement model have values large enough to cast doubt on the appropriateness of specification and other aspects of the fit of the model. Hence, all residuals whose modeling would result in a significant drop in the relevant $\chi^{2}$ value relative to one degree of freedom are included in the path diagram indicated in Figure 2. Because no significant parameters remain unaccounted for in the model, its overall fit must be considered optimal (Tuijnman, 1989)

Jencks et al. (1979, p. 98) express doubt about the size of the correlation found with Swedish data because it is lower than those found in some American studies. Jencks et al. $(1979$, p. 98) write that the difference may have arisen because the IQ test given to the 10 -year-olds was less reliable than the one given to the 20 -year-olds. From the factor loadings associated with the measures of child IQ and adult IQ in Figure 2, it can be inferred that the subtests given in childhood were, in fact, less reliable than those used a decade later.

That is, paths not shown are not significant at the $5 \%$ level. These paths were deleted before reduced form estimates were obtained. It should be noted that the data fit the model well because the estimated probability value ( 0.57 ) exceeds that of the $0.10 \%$ level of significance commonly used as a threshold level of accepting the goodness of fit of data to a LISREL model.

${ }^{8}$ The split-half reliability coefficients of the four test components used by the Swedish Armed Forces in the testing in 1948 of the males of the Malmö Study cohort were estimated by Husén and Henricson (1951, p. 32 ) on the basis of data collected in 1946 for 305 Swedish men. The reliability coefficients of the subtests used in 1948 can also be calculated from the factor loadings shown in Figure 2 . The similarity between these estimates is noteworthy, not least because it demonstrates the significance of advances made in statistical theory since the 1950s. Because of a lack of relevant information, Husén (1951a) and Härnqvist (1959) could not control for the insufficient reliabilities of the IQ tests given in 1938. As can be inferred from Figure 2, the LISREL technique used in the present study can not only be used to estimate them ex post facto but can also take the possibly biasing effect of residual covariances into account.

${ }^{9}$ The sum of the direct and indirect effects constitutes the total effect coefficient. It should also be mentioned that the direct effect coefficients included in this supplementary table are unstandardized maximum likelihood estimates. Thus, minor discrepancies may exist between the standardized path coefficients shown previously in Figure 2 . The estimates indicate that a minor but significant part $(0.15)$ of the total influence of child IQ on adult IQ (0.95) is mediated by formal schooling. Moreover, the data indicate that the unstandardized path coefficient obtained for the stability of the IQ from 10 to 20 years of age amounts to 0.80 (standard error $=0.04$ )

${ }^{10}$ However, care must be taken in comparing these path coefficients because they are obtained from studies involving compeltely different populations.

11These correlations can be considered "true," not because they are estimated using the maximum likelihood fit function but because they are found in a model in which biasing effects of measurement errors, residuals, and missing data are minimized.

${ }^{12} \mathrm{~A}$ note of caution must be made, however, because even though a strong correlation (0.89) is found between child IQ and adult IQ, other variables may contribute to this strong association.

${ }^{13}$ The analysis carried out in the present study could handle problems of analysis arising from autocorrelation, measurement errors, and missing data better than could analyses in previous studies. Compared with Husén (1951) and Härnqvist (1959), the results obtained in this investigation provide a more accurate and appealing means of assessing and interpreting the relationships studied. Moreover, the estimate of the influence of schooling on adult IQ (0.33) must also be considered more accurate than the corresponding estimate (0.45) found by Fägerlind (1975, p. 65), because in the latter study directly observed variables and OLS regression analysis are used.

${ }^{14}$ This seems reasonable, especially if one takes into account, first, that Härnqvist controls for the mediating effect of work conditions on adult IQ, and second, that Härnqvist measures dependent variables indicating verbal and linguistic skills at 32 years of age. Given these results, we feel confident in postulating that the "true" unstandardized schooling-IQ effect in Sweden, whereby the latter variable is measured between the ages of 20 and 30, probably lies fairly close to the value of 0.25 .

${ }^{15}$ It seems desirable to provide the reader with a rough check on data, theory, and model by combining the unstandardized schooling-IQ coefficient of 0.28 obtained in the Malmö study with national data on the average amount of IQ gain and mean schooling increase in Sweden over the period treated by Flynn. However, while data on the schooling increase are available, information about the IQ gain of 20 -year-olds is not readily accessible. Hence, several assumptions would have to be made if the calculation were to be carried out. Because the adequacy of the test and the reliability of the end result would thus remain in doubt, the authors decided to refrain from performing this check in the context of the present contribution. 


\section{References}

Anastasi, A. (1958a). Differential psychology (3rd ed.). New York: Macmillan.

Anastasi, A. (1958b). Heredity, environment, and the question "how." Psychological Review, 65, 197-208.

Anastasi, A. (1988). Psychological testing (6th ed.). New York: Macmillan.

Bayley, N. (1949). Consistency and variability in the growth of intelligence from birth to eighteen years. Journal of General Psychology, 75, 165-196.

Behrman, J. R., Hurbec, Z., Taubman, P., \& Wales, T. (1980). Socioeconomic success: $A$ study of the effects of genetic endowments, family environment, and schooling. Amsterdam: North-Holland.

Bergman, L. R. (1973). Parents' education and mean change in intelligence. Scandinavian Journal of Psychology, 14, 273-281.

Binet, A., \& Simon, T. (1905). Methodes nouvelles pour le diagnostic [New methods for diagnosing intellectual level in the abnormal]. Année Psychologique, 11, 191-244.

Bloom, B. S. (1964). Stability and change in human characteristics. New York: Wiley.

Boissiere, M., Knight, J. B., \& Sabot, R. (1985). Earnings, schooling, ability and cognitive skills. American Economic Review, 75, 1016-1030.

Bound, J., Griliches, Z., \& Bronwyn, H. H. (1986). Wages, schooling and IQ of brothers and sisters: Do the family factors differ? International Economic Review, 27, 77-105.

Bourdieu, P. (1979). La distinction. Critique sociale du judgement [Distinction: Social critique of judgment]. Paris: Editions de Minuit.

Bradway, K. P., Thompson, C. W., \& Cravens, R. B. (1958). Pre-school IQ's after twenty-five years: A follow-up. Journal of Educational Psychology, 52, 74-79.

Cronbach, L. J. (1960). Essentials of psychological testing. New York: Harper.

Coleman, J. S. (1988). Social capital in the creation of human capital. American Journal of Sociology, 94, S95-S120.

Emanuelsson, I., \& Svensson, A. (1985). Does the level of intelligence decrease? A comparison between thirteen-year-olds tested in 1961, 1966 and 1980 (Report No. 1985:02). Department of Education and Educational Research, University of Göteborg.

Fägerlind, I. (1975). Formal education and adult earnings: A longitudinal study on the economic benefits of education. Stockholm: Almqvist \& Wiksell.

Finch, F. H. (1946). Enrollment increases and the changes in the mental level (Applied Psychology Monographs No. 10). Chicago: University of Chicago Press.

Finn, J. D. (1988). Analysis of variance and covariance. In J. P. Keeves (Ed.), Educational research, methodology, and measurement (pp. 587-592). Oxford: Pergamon Press.

Flynn, J. R. (1987). Massive IQ gains in 14 nations: What IQ tests really measure. Psychological Bulletin, 17, 171-191.

Foshay, A. W. (Ed.). (1962). Educational achievements of 13-year-olds in twelve countries. Hamburg: UNESCO Institute of Education.

Fraser, B. J., Walberg, H. J., Welch, W. W., \& Hattie, J. A. (1987). Syntheses of educational productivity research. International Journal of Educational Research, 11, 145-252.

Freedman, D. A. (1987). As others see us: A case study in path analysis. Journal of Educational Statistics, 12, 101-128.

Haertel, G. D., Walberg, H. J., \& Weinstein, T. (1983). Psychological models of educational performance: A theoretical synthesis of constructs. Review of Educational Research, 53, 75-91.

Hallgren, S. (1939): Intelligens och miljö. En experimentell undersökning av barn in tredje skolaret vid Malmö folkskolor och privata skolor [Intelligence and social background: An experimental investigation of children in Grade 3 in public and private schools in Malmö], Vols. 1 \& 2. Unpublished licenciate thesis, University of Lund.

Hallgren, S. (1943). Grupptestning. Ett medel att minska kvarsittning $i$ folkskolor och hogre skolor [Group testing. A means of reducing grade repetition in primary and post-primary schools]. Stockholm: Gebers.

Härnqvist, K. (1959). Intelligensutveckling och skolresultat [Intelligence development and school achievement]. Nordisk Pedagogisk Forskning, $4,57-69$.

Härnqvist, K. (1968). Relative changes in intelligence from 13 to 18. Scandinavian Journal of Psychology, 9, 50-82.

Härnqvist, K. (1977). Enduring effects of schooling: A neglected area in educational research. Educational Researcher, 6(10), 5-11.

Härnqvist, K. (1989). Background, education and work as predictors of adult skills (research report). Department of Education and Educational Research, University of Gothenburg.

Hauser, R. M., \& Sewell, W. H. (1986). Family effects in simple models of education, occupational status and earnings: Findings from the
Wisconsin and Kalamazoo studies. Journal of Labor Economics, 4, S83-S115.

Husén, T. (1946). Intelligenskrav pa olika skolutbildningsstadier [Intelligence requirements at different stages of school education]. Skola och samhälle, 27, 1-23.

Husén, T. (1950). Testresultatens prognosvarde [The predictive value of test scores]. Stockholm: Almvist \& Wiksell.

Husén, T. (1951a). The influence of schooling upon IQ. Theorea, 17, 61-88.

Husén, T. (1951b). "Begavningsreserven" och den nya skolan. ["The reserve of ability" and the new school]. Folkskollärarnas Tidning, 32, No. 39.

Husén, T. (1953). The stability of intelligence test scores. Acta Psychologica, 9, 53-81.

Husén, T. (1962). Detection of ability and selection for educational purposes in Sweden. In Yearbook of Education, 1962. London: Evans Brothers.

Husén, T. (1974). Talent, equality, and meritocracy. The Hague: Martinus Nijhof.

Husén, T., \& Henricson, S. E. (1951). Some principles of construction of group intelligence tests for adults. Stockholm: Almqvist \& Wiksell.

Jencks, C., Bartlett, S., Corcoran, M., Crouse, J., Eaglesfield, D., Jackson, G., McClelland, K., Mueser, P., Olnick, M., Schwartz, J., Ward, S., \& Williams, J. (1979). Who gets ahead? The determinants of economic success in America. New York: Basic Books.

Jensen, A. (1969). How much can we boost IQ and scholastic achievement? Harvard Educational Review, 39, 1-123.

Jones, H. E. (1946). Environmental influences on mental development. In L. Carmichael (Ed.), Manual of child psychology (pp. 582-632). New York: Wiley.

Jöreskog, K. G., \& Sörbom, D. (1989). LISREL 7: A guide to the program and applications (2nd ed.). Chicago: SPSS Publications.

Kalton, G. (1983). Compensating for missing survey data. Ann Arbor, MI: Institute for Social Research, The University of Michigan.

Kish, L. (1987). Statistical design for research. New York: Wiley.

Lesourne, J. (1979). Economic dynamics and individual behaviour. In L. Levy Garboua (Ed.), Sociological economics (pp. 29-47). London: Sage.

Little, R. J. A., \& Rubin, D. B. (1987). Statistical analysis with missing data. Chichester: Wiley.

Lorge, I. (1945). Schooling makes a difference. Teachers College Record, $46,483-492$.

Lund, T., \& Thrane, V. C. (1983). Schooling and intelligence: A methodological study. Scandinavian Journal of Psychology, 24, 161-173.

McCall, R., Appelbaum, M., \& Hogarty, P. S. (1973). Developmental changes in mental performance (Monographs of the Society for Research in Child Development), 42(3).

Nesselroade, J. R., \& von Eye, A. (Eds.). (1985). Individual development and social change: Exploratory analysis. Orlando, FL: Academic Press.

Schaie, K. W. (Ed.). (1983). Longitudinal studies of adult psychological development. New York: Guilford.

Schaie, K. W., \& Hertzog, C. (1986). Toward a comprehensive model of adult intellectual development: Contributions of the Seattle Longitudinal Study. In R. J. Sternberg (Ed.), Advances in the psychology of human intelligence (Vol. 3, pp. 79-118). Hillsdale, NJ: Erlbaum.

Skeels, H. M. (1942). A study of the effects of differential stimulation on mentally retarded children: A follow-up report. American Journal of Mental Deficiency, 46, 340-350.

Skeels, H. M. (1965). Adult status of two groups experiencing early intervention. A follow-up study of the effects of differential stimulation on mentally retarded children. Washington, DC: National Institute of Mental Health.

Terman, L. M. (1916). The measurement of intelligence: The Stanford revision of the Binet-Simon intelligence scale. New York: Houghton Mifflin.

Terman, L. M., \& Oden, M. H. (1947). Genetic studies of genius: IV. The gifted child grows up. Stanford: Stanford University Press.

Tuijnman, A. (1989). Recurrent education, earnings, and well-being: A 50-year longitudinal study of a cohort of Swedish men (Acta Universitatis Stockholmiensis). Stockholm: Almqvist \& Wiksell.

White, K. R. (1982). The relation between socioeconomic status and academic achievement. Psychological Bulletin, 91, 461-481.

Williams, T. (1976). Abilities and environments. In W. H. Sewell, R. M. Hauser, \& D. L. Featherman (Eds.), Schooling and achievement in American society (pp. 61-102). New York: Academic Press.

Wolfle, L. M. (1980). The enduring effects of education on verbal skills. Sociology of Education, 53, 104-114.

Zajonc, R. B., \& Bargh, J. (1980). Birth order, family size, and decline of SAT scores. American Journal of Psychology, 35, 662-668. 